It is Time to Stop Talking and Start Doing: The Views of People with Learning Disability on Future Research

Anna Marriott ${ }^{1}$, Val Williams ${ }^{1}$, Ruth Townsley ${ }^{1}$

${ }^{1}$ University of Bristol 


\title{
'It is Time to Stop Talking and Start Doing': The Views of People with Learning Disabilities on Future Research
}

\author{
Anna Marriott, Val Williams, Ruth Townsley
}

\begin{abstract}
There is a need for people with learning disabilities to be involved in directing research to ensure that the research is meaningful to those it concerns. This paper describes a scoping exercise to determine the research priorities for the field of learning disabilities for the next ten years. It focuses specifically on the role of people with learning disabilities in setting this research agenda and describes the methodology used, which involved a series of consultation workshops. Analysis of the data from these generated six priority themes: access to health care; getting good support; the right to relationships; housing options; work and personal finance; inclusion in the community. The findings showed that it is possible for people with learning disabilities to participate in setting a research agenda and there was agreement between the different stakeholders on the fundamental priorities. Moreover, the inclusion of people with learning disabilities provided a perspective that could not be adequately represented by other stakeholder groups. People with learning disabilities were concerned that research has a meaningful impact and can lead to demonstrable improvements in care. In order for this to happen there is a need for widespread dissemination of accessible outputs that reach the relevant stakeholders.
\end{abstract}

Key words: Learning Disabilities, Research, User Involvement, Inclusive Research, Participation, Empowerment

\section{Background}

People with learning disabilities are one of the most socially excluded groups in today's society (Department of Health 2009). It is important that research helps us to understand how to move towards equality for people with learning disabilities. Therefore research needs to be focused on the areas of concern for people with learning disabilities themselves. Although people with learning disabilities are increasingly being more involved in research projects (Walmsley and Johnson 2003), their participation is often only considered once a project has been designed and funding obtained. For learning disability research to be emancipatory (Oliver 1992) it must stem from the agenda of people with learning disabilities, but this is still rare.

This paper describes a scoping exercise to determine the research priorities for the field of learning disabilities for the next ten years (Williams, et al., 2008). It was funded by the National Institute for Health Research (NIHR) and the overall aim of the study was to work with relevant stakeholders to reach a consensus on the research gaps that need addressing. People with learning disabilities themselves, as well as their family members, were therefore considered in this study to be the key stakeholders and this paper focuses specifically on the role of people with learning disabilities in setting this research agenda. There is a detailed description of the methodology used for the consultation process and the findings that came from this, as well as reflections on the role of people with learning disabilities and what their inclusion contributed to the project. 


\section{Methodology}

The design was intended to prioritise the areas of greatest concern in the lives of people with learning disabilities and a qualitative, narrative approach was employed.

\section{Stage One}

The first stage of the study involved a series of consultations, which were undertaken at regional workshops held in Bristol, Birmingham, Leeds and London. The aim of these workshops was to identify the main issues and problems in the lives of people with learning disabilities. At this point the focus was on individuals telling their own stories and voicing their concerns rather than on possible research questions. This is allied to a narrative approach, which foregrounds the voice of the research participants (Atkinson and Walmsley 1999).This research was commissioned in order to support social policy and therefore it explored the experiences of people with learning disabilities and the support and services they receive, rather than any medical conditions they might have.

The study was conducted by a university research centre that specialised in research with, and about, people with learning disabilities, and had an established advisory group called an 'Ideas Group'. This group comprised representatives of local self-advocacy/People First organisations and was central to the planning and delivery of these workshops. Involving people with learning disabilities in research can be done at many levels (Walmsley and Johnson, 2003). In some research designs, people with learning disabilities may act as primary researchers (Williams, et al 2005). However, it is also possible for people to act as advisors to research projects (Tarleton et al 2004). In the current approach, the advisory group progressively took on a more active role within the research, by both planning and leading workshops. The structure of the workshops was designed to foreground the views and issues raised by people with learning disabilities themselves, although it was also important that other stakeholder groups were able to have a voice. There was a morning session solely for people with learning disabilities, which ensured there was time to explore the purpose of the workshop and that their views were central to the day. Following a warmup activity run by the Ideas Group, participants shared their thoughts on what research was, to set the scene. They then worked in smaller groups; each of these was facilitated by a member of the research team and a member of the Ideas Group and used a selection of pictures to identify areas that might be of concern in their own lives. The morning session concluded with feedback from each group and participants then reached an overall consensus as to the issues they considered to be of the highest priority.

The other participants (family members and professionals) joined each workshop at lunchtime and the afternoon session began with feedback from people with learning disabilities, in order that their views provided a backdrop for subsequent discussions. Professionals and family members worked in small groups to identify what they felt were the crucial issues in the lives of people with learning disabilities. Meanwhile the majority of the self-advocates worked with pictorial facilitators to explore their personal dreams for the next ten years; some of the self-advocates chose to join the discussion groups instead. A final feedback session was held in which the self advocates talked through the pictures of their dreams and all groups shared the main points of their discussions. Data collected during the workshop sessions were scribed onto flip-charts and the discussions were audio-recorded and subsequently transcribed and thematically analysed (Braun and Clarke 2006). The analysis of these data generated a list of the priority themes which were the issues that had been mentioned most often and agreed on in feedback with all the stakeholder groups.

These priority themes were:

- access to health care 
- getting good support

- the right to relationships

- housing options

- work and personal finance

- inclusion in the community.

\section{Stage Two}

The priority areas were subsequently reviewed at a project steering group meeting and used as the basis of the search terms. A network of researchers in the UK was consulted for comment on these. A systematic literature review was conducted, using these search terms, in order to identify all UK research published since 2001 that related to the six themes. The inclusion criteria for the literature to be included in the critical appraisal process were that the material should be:

- related to people with learning disabilities

- U.K. based

- written in English

- published in 2001 or afterwards

- about a research study, or a research review, relevant to the social life of people with learning disabilities.

Nine databases were searched for relevant research papers (see Appendix A for further details of databases and search terms). The titles and abstracts were reviewed to identify relevant research and the reasons for exclusion were noted. Additionally, reference lists of studies were checked to identify other related research and hand-searching of key academic journals and practitioner magazines was undertaken. Experts in the field of learning disability were contacted in an attempt to identify further relevant published studies or any grey literature pertaining to the review, in order to minimise publication bias.

The research team developed a reading tool for data extraction and quality appraisal of all the research articles identified by the literature review. This detailed the type of research, the main aims, methodology and findings of each paper, as well as details relating to sample size, analytical methodology, the level of inclusion of people with learning disabilities in the research, ethics and policy and practice relevance. Each paper was also appraised on a scale of 1-5 for methodology, ethics, sample size, references and usefulness. In order to check for consistency, the two main researchers (Marriott and Williams) met in order to compare a sample of scorings, and criteria for the scoring were revised. The scores enabled the overall 'quality' of the research studies to be estimated in order to gauge their effectiveness in contributing to knowledge and therefore inform the research review.

\section{Stage Three}

Following the literature review, further work was carried out to involve people with learning disabilities directly in developing the research agenda. At this stage, a second round of consultation workshops was held in all four geographical areas again, to which the same participants were invited. These workshops were challenging, partly because the identification of research 'gaps' is not an exact science. In order to set the scene for identification of gaps and priorities in research, it was essential to present summaries of the research reviews that had been undertaken by the research team. The structure of the workshops was similar to the first round, with people with learning disabilities attending a pre-meeting. The warm-up activity had been developed in conjunction with the Ideas Group and was designed to help participants start to explore concepts around choices and priorities. Following this, participants were asked to select a 'priority theme' that was important to them and to share their own detailed stories and recent experiences in that 
area. Stories were visually recorded, and fed back to open the full workshop session in the afternoon. This method enabled the research team to capture individual narratives and it helped participants to refer back to their lived experiences and to consider how research could have a purpose in these real-life events. The stories that participants told varied in both mood and topic; some people described their daily experiences of bullying whilst others spoke about independent travelling and their goals.

In two of the workshops, groups of people with learning disabilities were also asked about their ideas for how research should be carried out. They were given a 'real' research question from an existing research paper, and then they talked through how they would tackle it, by posing concrete questions about where the research would take place, who would do it and what they would do.

As in the first round of workshops, professionals and family members joined the workshops at lunchtime. There was feedback from the morning sessions and the research team presented the findings of the literature review. This was a crucial stage in the study as it was vital to ensure the proposed research priorities built on the existing evidence-base and identified research questions that had not yet been addressed. Following the presentations about the literature review, participants split into mixed groups (of different stakeholders) to discuss two main thematic areas per group. Each group received a summary of the literature review in those areas, and discussed both the gaps in research that had been revealed and the ways in which they would prioritise those gaps. Summaries of the findings from the literature search were presented to participants and they worked within groups to reach agreement on research priorities. They also began to explore issues about research process and what type of research is needed, as well as the questions that need to be answered.

In the final feedback session all the 'research gaps' that had been identified were put up onto a wall chart, and participants were asked to reach a consensus on which ones they would fund first. Data from these groups were recorded and thematic analysis was used to identify the main priority areas. The final consensus exercise in these workshops proved extremely difficult, as all the research questions that had been discussed seemed to be important and individuals often found it impossible to reach a definitive conclusion. Therefore the full report of this scoping exercise identified a range of questions generated during the consultation, under each of the main priority themes.

\section{Stage Four}

The methodology used in the scoping exercise was deliberately developed to ensure that the voices of people with learning disabilities were strongly reflected in the findings. It was important to the research team that the opinions of professional researchers did not dominate the agenda and therefore face-to-face consultation with the network of researchers in the field was only undertaken at this stage. This was done via a focus group with nine academic researchers from the UK with a background in the field of learning disability and with a range of methodological approaches. The research team presented the emerging findings of the scoping exercise and asked the researchers to respond to these, rather than set their own agenda. Transcribed data from the focus group was thematically analysed to identify the research priorities highlighted and other relevant issues about research processes which were discussed. This process generated minimal dissension; in general the academic researchers agreed with the priorities identified by the stakeholder workshops and felt they had a high degree of concurrence with their own views.

\section{Stage Five}

The findings from the analysis of stages three and four were collated in a questionnaire 
which was sent out to 15 national development and policy organisations. These were chosen to represent a spread in focus and included groups concerned with advocacy, self-advocacy, mental health and other health issues, and practical policy-related support. The questionnaire aimed to explore how these organisations viewed the research gaps identified in the scoping exercise and how they perceived them to fit with their own agenda.

\section{Results}

The full findings of the results that emerged from the above stages of work can be found in Williams et al (2008). For the purpose of this paper there is a brief summary of the findings within each of the identified priority areas, with a particular emphasis upon the views of the participants with learning disabilities.

\section{Access to Health Care}

The themes of accessible information and communication were evident within most of the topics discussed but it was particularly central to the concerns of people with learning disabilities about access to healthcare. Participants were clear that they have a right to access ordinary primary and secondary healthcare services but, in order for this to be possible, they must be able to understand what services are available and then be able to successfully communicate with the healthcare professionals. The comment by one woman is representative of what many participants reported:

I went to the GP with my mum, but he only spoke to her. My mum told him not to do that, but I couldn't get my point across at all. I gave up really, because I couldn't understand what was going on.

There was widespread agreement that many mainstream health professionals do not have sufficient understanding about learning disability issues and that this negatively impacts on the care these people can provide.

An important initiative introduced at the time of the English Learning Disability Strategy (Department of Health 2001) was Health Action Plans (Department of Health, 2002) and people with learning disabilities who attended the workshops focused on these. Many were unsure of how to get a Health Action Plan and were unconvinced that many people have one and of their impact. They wanted research to address these issues.

The emphasis on the research gaps within the area of access to healthcare was very much on practical, action-based research which would help people with learning disabilities to have fairer access to generic health services.

\section{Getting Good Support}

People with learning disabilities were often concerned about the availability of good support staff and recognised that they need good quality support to have increased choice and control over multiple aspects of their lives. People's stories made some references to support staff who patronised them or made them feel small. It is clear that the relationship with the support worker was absolutely vital to individuals and people wanted to choose which staff supported them and were able to articulate qualities they considered to be essential. It was stated by many that qualifications do not always matter and the right attitude from staff has a greater effect on the quality of care provided than training or qualifications. People said they preferred consistency in staff-teams and many spoke about staff leaving and the impact of this. Participants in our workshops felt there is a need for research to explain the factors which influence low and high turnover of staff, the availability 
of support staff for individual budget users, and motivation of staff. This builds on research which has revealed that over a third of support staff were likely to seek new employment in the following year (Robertson et al 2005).

\section{The Right to Relationships}

People with learning disabilities often spoke about other people in their lives, including family members, friends and partners and it was evident that relationships are central to their happiness. Out of all the areas in this consultation and review, the topic of 'relationships' was perhaps the most difficult to translate into research questions. Although workshop participants felt very strongly about relationships, they had some difficulty in thinking how the gaps in our knowledge could be met by research.

Existing research points up the very thin social networks of many people with learning disabilities in the UK (Forrester-Jones et al 2006). Participants agreed and said that their relationships may often not be taken seriously enough and that the importance of friendships and sexual relationships was easily dismissed by professionals. This was reflected in some of the participants' narratives; one man spoke of his personal bereavement when a close friend died and the lack of acknowledgement that he would need appropriate support at this difficult time. People at the workshops said that the priority for research in this area was to move on and seek evidence-based solutions to underpin practice.

Participants were keen to highlight the fact that they are not always the person in need of support and that some people with a learning disability may find themselves in a carer's role and this could be in relation to their own children, a disabled partner or ageing parents. They spoke up about the lack of recognition given to them in that role:

Research needs to look at us as carers. We don't get any recognition and support. But we don't even know how many people with learning disabilities are actually caring for other people.

The thematic analysis showed that sexuality and parenting were highlighted as important areas for future research by the people with learning disabilities at the workshops. For instance, they suggested research questions which would explore the experience of children who remain with their birth parents in comparison with those who are removed from the family.

\section{Housing Options}

One of the main concerns of people with learning disabilities in relation to the issue of housing pertained to the lack of choice.

People should live in the home that is right for them, so young adults shouldn't be made to live in a home where everyone else is a lot older.

It is salutary to remember that the vast majority of people with learning disabilities in the UK have not chosen the people they live with (Emerson et al 2005). People with learning disabilities were keen to see research which explores how to facilitate better choices for them in regard to where, and with whom, they live. There was a call for research which highlights good practice in giving people real housing options (including home ownership, shared ownership and renting), good information, and choice about who to live with.

Participants were able to identify particular groups who are most affected by lack of choice in terms of their housing. This included people in wheelchairs and those with high support 
needs, including people with challenging behaviour. It was felt that research could look further at personalised living arrangements for these people, and that could be backed up by evidence about current arrangements - in residential care and especially in out-of-area placements.

\section{Work and Personal Finance}

Employment was an issue of great importance to people with learning disabilities in our consultation. By contrast with the traditional job menu of trolley-pushing and catering work, people in our workshops talked about the contributions that they had personally made to the Disability Rights Commission or to research projects where they had had paid jobs. However, the issue of paid work was contentious; research has shown continuously that benefits are still posed as a 'barrier' to paid employment (Schneider et al 2001). As one person at a workshop said:

I like voluntary jobs because they don't upset my benefits.

Some of the participants felt that there is a need for more research about the advantages of voluntary work whilst others felt it was more important that research is used to identify ways in which the barriers to paid employment (including benefit issues and employer attitudes) can be overcome. More specifically, one of the research questions that people with learning disabilities proposed was to find out how many people with learning disabilities are taking advantage of the Department for Work and Pensions' Access to Work scheme and how this could be more accessible and easier to manage.

\section{Inclusion in the Community}

People in all four workshops spoke about wanting to get out, and do things outside their own home, within the wider community. However they also identified many barriers in doing ordinary things, such as shopping or going to the cinema. These included both physical barriers such as lack of access but people also felt excluded as a consequence of other peoples' attitudes and how they were treated. Above all, people spoke of worries about bullying and hate crime. It was the attitudes of other people (outside the family and outside the service world) which were of greatest concern and peoples' experiences of participating in their local community were regularly marred by name-calling, bullying and sometimes downright abuse. The individual narratives suggested these are not new issues but rather that they are just beginning to be taken seriously. People agreed that we still lack evidence of the scale and gravity of the problem; they identified a need to explore the numbers of people with learning disabilities who are affected by hate crime, as well as the effect of it and the possible links with mental health problems. Participants also spoke about the need to understand how such attitudes are formed:

We need to educate more people, who haven't got disabilities. The rest of the community.

This is a particularly important issue currently, as a greater number of people with learning disabilities are living semi-independently or with minimal support (Fyson et al 2007).

It was clear from people's narratives that many people with learning disabilities would like to have more active and fuller lives, but that currently they are constrained by: lack of choices; lack of support; transport problems; limited money and concerns for safety. Again, their experiences corresponded closely to what had been revealed in the literature, as there was existing evidence about barriers to community access (Abbott and McConkey 2006). There are difficult issues for people in getting the balance right between risk-taking and safety; the 
research gap identified by people with learning disabilities was about the positive strategies that could be adopted in supporting community engagement. There is a role for research in tackling the very ordinary barriers which people face, such as the confusing nature of railway stations, maps and timetables, and use of mobile phone technology.

\section{Cross Cutting Themes}

The division of research priorities and concerns into six areas was, to some extent, an artificial measure. People's lives are holistic, and the concerns they raised in the workshops were about their whole lives. Many of the studies in the literature review, accessed under one search term, were also applicable to other areas. Additionally, some of the themes raised in workshops could be traced through all six of the priority areas, and are essentially cross-cutting themes. Some of these related to specific groups of people with learning disabilities.

\section{People with Profound and Multiple Learning Disabilities (PMLD)}

People with PMLD are often excluded from research studies for a number of reasons. It is notoriously difficult to ensure that fully informed consent is obtained from this group and they are often excluded from research on the grounds that they lack capacity. Additionally, many qualitative studies, in particular, rely on verbal interviews, and it is a challenge for researchers to realistically include people with PMLD in interviews. The literature review showed that the specific needs of this group are often overlooked, even within large-scale research studies. It is easy for the analysis to then overlook the different and specific issues that might arise for people with PMLD, as opposed to other groups. For instance, in studies about support workers, the topics of sensory methods and practical care skills will only be applicable to some sub-groups of people with learning disabilities, not to all. In studies about health, it is vital to distinguish those who really will not be able to report their symptoms, from those who simply need more time in order to do so.

In the present study it is likely that people with PMLD may well have a different agenda for research priorities to those who have lower support needs. Therefore it was crucial that their views were represented and the workshops were attended by some participants with higher support needs, including two who used non-verbal communication. They were not the only participants to highlight the specific needs of people with PMLD. However, it is possible that their inclusion in the debate/workshops served as a reminder to all participants that people with learning disabilities are not a homogeneous group and have varying needs.

\section{People from Black and Minority Ethnic (BME) Communities}

The literature searches in all six priority areas only revealed two papers which specifically focused on people from BME communities. Evidence suggests that it is often difficult to recruit people from BME communities to research projects as they tend to have less contact with services overall. In relation to all the priority areas there was often discussion around cultural issues and yet there is a paucity of research exploring what these cultural issues actually are. There is a particular need to ensure that people with learning disabilities from BME groups are represented in health research as they may have specific health issues as well as particular difficulties in accessing health services.

It might not always be the case that specific research is needed, to focus on these particular groups. In many cases, generic research outside the field of learning disability could inform the evidence base. For example, although there is a dearth of health based research in relation to people with learning disabilities from BME groups, there is a much more robust evidence base about the health needs of people from BME groups within the general 
population. However, findings from other research will need to be specifically applied to the situations in which people with learning disabilities live and work.

\section{Research Process}

It was clear from the first workshop that the participants with learning disabilities were able to articulate views on the type of research they wanted as well as the questions they wanted it to answer. People said that research should be about knowledge, but also about action and certainly about changing things. A crucial aspect of this relates to research reaching the people it concerns. The vast majority of research findings are published in academic journals which are unlikely to be read by front-line support staff, for example. Equally there needs to be a stronger emphasis on accessible research findings so people with learning disabilities themselves are able to find out what research has been done.

At one workshop, a group met in the afternoon session and came up with some interesting ideas for a new type of research agenda. They suggested an agenda where action research would be led by groups of people with learning disabilities, who would generate their own research questions and use the findings directly in their work. In this way, research becomes part of a business venture, and is entirely controlled by disabled people, fulfilling the original idea of 'emancipatory research' (Oliver 1992).

\section{Discussion}

The aim of this scoping exercise was to achieve a consensus about the priorities in Learning Disability research for the next ten years, by involving as many different groups of stakeholders as possible. The identification of research 'gaps' is not an exact science and although there were some differences between the perspectives of the various stakeholder groups, there was agreement on the fundamental priorities. This was reflected not only in the thematic analysis of the data relating to research topics but also in the emphasis that all stakeholder groups placed on the need for research to be better linked with changes in practice. It was clearly important to participants that research has a meaningful impact and can lead to demonstrable improvements in care for people with learning disabilities.

The findings demonstrate it is possible for people with learning disabilities to participate in setting a research agenda. The topic of 'research priorities' is a difficult one to conceptualise and therefore a face-to-face method of consultation was selected in preference to a survey approach. Whilst a survey would have had the advantage of including a larger number of people in the consultation, it would be difficult to reach a 'consensus' with this methodology. Ensuring all views are listened to in a consultation exercise involves taking account of power relationships (Fairclough 1995). Although this study did not use Critical Discourse Analysis, it took account of the fact that power relationships are embedded in all discourse. In common with other social research in this tradition (Oliver 1992, Barnes and Mercer, 1997) this research methodology would not claim to be 'value neutral'. The aim was to ensure that weight was given to the voices of stakeholders who attended the workshops, most of whom had direct, lived experience of learning disability. It was important to establish a methodology that permitted them to set the agenda, based on issues in their own lives.

The methodology employed for the scoping study enabled all participants to have an opportunity to offer their views and to interact during discussions. Consequently, to some extent, their views will be a reaction to what others have said. One of the limitations of this approach is that group dynamics can mean some participants are dominant and others may find it difficult to be heard. The workshop format gave precedence to the views of people with learning disabilities; the aim of the pre-session was to provide an opportunity for them to formulate their own opinions and gain confidence in their views. This structure provided a 
clear way to ensure that the voices of people with learning disabilities themselves were strong. The research team were encouraged by the fact that, although the afternoon sessions had been designed to provide options for the separate groups of stakeholders, this was not always adhered to. Participants chose to mix their groupings and on the whole this resulted in interesting group discussions with varied perspectives represented.

Although the level of consensus reached in relation to the main priority themes was encouraging, there were also some differences between the approaches of the stakeholder groups, demonstrating the need to actively involve all stakeholders in a study of this type. For example, people with learning disabilities tended to identify areas in their lives that could be improved and were able to articulate what could be better in relation to living arrangements, jobs and support etc. However, they were less likely to discuss how these changes could come about and the mechanisms needed to secure them. Some of the other stakeholders identified the need for research around some of these mechanisms for change, such as person centred planning and individual budgets. Financial issues were discussed by all stakeholder groups but there were some differences in how the groups felt this topic should be represented in terms of the research agenda. The researchers at the focus group felt that there is a need for more research which looks at the changing patterns of poverty and wealth in the UK, in order to see exactly how people with learning disabilities and their family carers fit into these patterns. In contrast, although people with learning disabilities generally felt they wanted more money, they were primarily concerned with issues around their management and understanding of their personal finances.

The inclusion of all stakeholder groups in the consultation helped to widen the remit of the research agenda that was identified. For example, some of the participants with learning disabilities did not identify the need for the research around paid work, on the basis that they did not want to risk losing their benefits. There seemed to be a degree of acceptance in relation to this issue for some people with learning disabilities, whereas professionals and family members were keen that research should explore alternative models to the existing benefits system, such as disability pensions.

This scoping exercise was a very substantial undertaking. There were certain limitations, most of which sprang from inherent difficulties in the task of reaching consensus on research priorities. It is intellectually challenging to review research knowledge and identify gaps in that knowledge, and it is also challenging to determine whether those gaps actually need to be filled and whether research findings could do this. Therefore, the demands on all the relevant stakeholders were very great and yet the analysis of the data showed participants with learning disabilities had been able to contribute greatly to the consultation. Their involvement added strength to the scoping study, as they provided a perspective that could not be adequately represented by either their family or professional carers. It also underlined the importance of other stakeholders not making assumptions about the views of people with learning disabilities. For example, discussions about support generally referred to the fact that people need more support and of a higher quality. However, one participant was adamant that he had too much support and felt this limited him. Therefore any relevant research questions need to be framed around ensuring people have the 'appropriate' amount of support, rather than 'enough' support. Furthermore, data analysis revealed that people with learning disabilities did not always approach the discussions from their own, personal perspective; they were also able to provide insights on behalf of others. This was highlighted by the consistent emphasis on the particular needs of people with PMLD by people who had lower support needs themselves. Additionally, they identified the problems around poor pay and working conditions for frontline support staff. Traditionally, support staff have often been asked to provide data on behalf of people with learning disabilities and it was interesting to see these roles instinctively being reversed.

In order to ensure the consultation made sense, it was necessary to develop ideas about 
what research could and could not do. In the workshops, these issues were hotly debated. People with learning disabilities were actively involved in these debates and they talked about 'research which helps us to understand things', and wanted 'research to find things out, so we can change our lives'. For most of the stakeholders at the workshops, this was not a theoretical subject, but one which was of vital importance to their daily lives. The frustration with research which does not deliver change was a very keen one. The literature review highlighted the volume of research that had already been conducted within our priority areas. It was clear from the consultation that all stakeholders often posed questions on which research had already been done, possibly because research findings often do not reach the relevant stakeholders. This provides further support for the call for accessible outputs to be widely disseminated in order to ensure the findings do reach the people for whom they can have an impact. Research cannot make an impact if it fails to reach the target audience, and the participants were clear that there is no value in research that does not have a practical focus and will not lead to change. This is reflected in the fact that the workshop participants focused on research that is about how to make change happen and how to maintain this. In all the priority areas, participants wanted research that looked at good practice and the factors that enabled this.

Finally, the consultation also showed the need to broaden horizons and to move outside of the field of learning disability. There are lessons from other fields, such as research findings about successful change management, which could help inform existing systems within learning disability. Moreover, perhaps it is no longer sufficient to measure standards within the learning disability service world. Participants spoke about the need to move towards comparisons with the general population, rather than studies only exploring issues for people with learning disabilities. An example of this type of research was a suggestion to compare the experience of people with learning disabilities with non-disabled people in obtaining a job. Within all of the priority areas there is a need to look towards research designs which will provide a comparative measure and judge what happens for people with learning disabilities by the same standards as everybody else. 


\section{Appendix A}

\section{Databases}

The following databases were searched for relevant research papers:

- $\quad$ IBSS (BIDS)

- $\quad$ ASSIA

- British Education Index

- SCIE

- CINAHL

- $\quad \mathrm{SSCl}-$ Web of Science

- Sociological Abstracts

- Cochrane Library

- Dissertation Abstracts

\section{Search Terms}

All search terms from the individual themes (see below) were combined with:

- learning dif* $^{\star}$

- learning dis*

- intellectual disabilities

- mental retardation

- mental handicap

\section{Search Terms for "Health"}

Health action plan*

Health + information/advice

Diet

Exercise

Health + accessible information

Health professionals + communication

Health professionals + continuity

Health + appointment*

Healthcare access

Health + special $^{*}$

Dent*

Health + inequalit*

Mental health

Health + medication

Cancer care

Palliative care

Dementia care

Postural care

Pain management

Dysphagia

Health + therap*

Health + management

Hospitals/acute care

Health + targets

Health + research 


\section{Search Terms for "Support"}

Staff/support workers + working conditions

Staff/support* and choice

Staff/support ${ }^{*}+$ relationship

Staff/support ${ }^{\star}+$ flexibility

Staff/support + person-centred planning

Staff/support + independence

Staff/support + communication

Staff/support + qualifications

Staff + quality of support

Staff/support + direct payments

Staff/support + problems/difficulties

Staff/support + ethnic*

Staff/support + quality

Staff/support + eligibility

Staff/support + regulation

Individualised support

Support + safety/risk

Staff/support + employ*

Staff/support + options

Staff/support + in-control

Staff/support + individualised budgets

Workforce/staff/professionals/supporters

Workforce/staff/professionals/supporters + attitudes

Workforce/staff/professionals/supporters + training

Workforce/staff/professionals/supporters + job satisfaction

Workforce/staff/professionals/supporters + relationship*

Workforce/staff/professionals/supporters + communication

Workforce/staff/professionals/supporters + pay

Workforce/staff/professionals/supporters + recruitment

Workforce/staff/professionals/supporters + impact of

Workforce/staff/professionals/supporters + qualification

Workforce/staff/professionals/supporters + abuse

\section{Search terms for "Friendships, relationships and parenting"}

Friends*

Relations*

Dating

Marriage

Friends* + loss

Relations ${ }^{*}+$ sex $^{*}$

Parents with learning di*

Famili* + gate-keepers $^{*}$

Parents + information

Parents + pregnancy

Parents + support

Parents + attitude 


\section{Search terms for "Housing"}

Housing

Supported living

Independent living

Residential care

\section{Search terms for "Work and money"}

Employ*/job* + pay

Employ*/job* + benefits

Employ*/job* + minimum wage

Employ*/job* + hours

Employ*/job* + discrimination

Employ*/job* + disability discrimination act

Employ ${ }^{*} /$ job $^{*}+$ risk ass*

Employ*/job* + work experience

Employ ${ }^{\star} /$ job* $^{*}+$ choice

Employ $* / j o b^{*}+$ CVs

Employ*/job* + interview*

Employ ${ }^{*} / \mathrm{job}^{*}+$ training

Employ*/job* + gender

Employ*/job* + high support needs

Employ*/job* + exploitation

Supported employment

Employ*/job* + support

Money + support

Money + bank ${ }^{*}$

Money + capacity

Benefits + savings

Money management

Financial abuse

\section{Search terms for "Inclusion in the community"}

Leisure activities

Transport

Sport

Holidays

Community + access + barriers

Community + safety

Community + independence

Community + choice

Community + inclusion

Community + support

Accessibility

Access ${ }^{*}+$ community

Access $^{*}+$ services

Accessible information

Hate crime 


\section{References}

Abbott, S; McConkey, R., 2006. The Barriers to Social Inclusion as Perceived by People with Intellectual Disabilities. Journal of Intellectual Disabilities 10: 275-87.

Atkinson, D; Walmsley, J., 1999. Using Autobiographical Approaches with People with Learning Difficulties. Disability and Society 14:.203-216.

Barnes, C; Mercer, G., 1997. Breaking the Mould? An Introduction to Doing Disability Research. In: C. Barnes, \& G. Mercer, eds. 1997. Doing Disability Research. Leeds: The Disability Press. Ch.1.

Braun, V; Clarke, V., 2006. Using Thematic Analysis in Psychology. Qualitative Research in Psychology 3: 77-101.

Department of Health. 2001. Valuing People: A New Strategy for Learning Disability in the 21st Century: A white paper. London: Department of Health.

Department of Health. 2002. Action for Health, Health Action Plans and Health Facilitation Detailed Good Practice Guidance on Implementation for Learning Disability Partnership Boards. London: Department of Health.

Department of Health. 2009. Valuing People now: a new Three-Year Strategy for People with Learning Disabilities. London: Department of Health.

Emerson, E; Malam, S; Davies, I; Spencer, K., 2005. Adults with Learning Difficulties in England 2003/4. Full Report. NHS Health and Social Care Information Centre.

Fairclough, N., 1995. Critical Discourse Analysis: The Critical study of Language. London and New York: Longman.

Forrester-Jones, R; Carpenter, J; Coolen-Schrijner, P; Cambridge, P; Tate, A; Beecham, J; Hallam, A; Knapp, M; Wooff, D. 2006. The Social Networks of People with Intellectual Disability Living in the Community 12 Years after Resettlement from Long-Stay Hospitals. Journal of Applied Research in Intellectual Disabilities 19: 285-95.

Fyson, R; Tarleton, B; Ward, L., 2007. The Impact of the Supporting People Programme on Housing and Support for Adults with Learning Disabilities. Joseph Rowntree Foundation.

Oliver, M., 1992. Changing the Social Relations of Research Production? Disability and Society 7: 101-14.

Robertson, J; Hatton, C; Felce D; Meek, A; Knapp, M; Hallam, A; Emerson, E; Pinkney, L; Caesar, E; Lowe, K. 2005. Staff Stress and Morale in Community-Based Settings for People with Intellectual Disabilities and Challenging Behaviour: A brief report. Journal of Applied Research in Intellectual Disabilities 18: 271-77.

Schneider, J; Simons, K; Everatt, G., 2001. Impact of the National Minimum Wage on Disabled People. Disability and Society 16: 723-47.

Tarleton, B; Williams, V; Palmer, N; Gramlich, S., 2004. An Equal Relationship? People with Learning Difficulties Getting Involved in Research. In: M. Smyth, \& E. Williamson, eds 2004. Researchers and Their 'Subjects': Ethics, Power, Knowledge and Consent. Bristol: Policy Press. Ch.4. 
Walmsley, J; Johnson, K., 2003. Inclusive Research with People with Learning Disabilities: Past, Present and Futures. London: Jessica Kingsley.

Williams, V; Marriott, A; Townsley, R., 2008. Shaping our Future: A Scoping and Consultation Exercise to Establish Research Priorities in Learning Disabilities for the Next Ten Years. Report for the National Co-ordinating Centre for NHS Service Delivery and Organisation: http://www.sdo.nihr.ac.uk/sdo1522006.html

Williams, V; Simons, K; Swindon People First Research Team, 2005. More Researching Together. British Journal of Learning Disabilities 32:1-9. 
